\title{
TIPOLOGIA DOCUMENTAL DE ALFONSO V: NOMBRAMIENTOS DE ALCAIDES EN ALICANTE
}

\author{
María Luisa Cabanes Catalá
}

En 1416 cuando muere en Perpiñan Fernando I, le va a suceder su hijo Alfonso V. Este rey va a sentir vocación por Italia, hasta tal punto que parte de su vida va a transcurrir en la zona sur de esta Península y será precisamente a través de este contacto con Italia cuando fructificará y se introducirá en la Corona de Aragón la nueva escritura, la que se pone a lo bárbaro, a lo gótico, la escritura humanística.

El objetivo de este trabajo va a ser el análisis diplomático y paleográfico de un grupo de documentos contenidos en el Archivo del Reino Valencia en el volumen que lleva la signatura, Real Cancilleria 24, "De castrorum Valentie» (1)

La sistematización del estudio de estos documentos será la siguiente:

1. - La fuente

2. - Estudio de los documentos

2.1. - Paleográfico

2.2. - Diplomático

3. - Apéndice

(1) Desde ahora nos referiremos a él como: A.R.V., Real Cancillería, 24. 
De todos los registros que se custodian en el Archivo del Reino de Valencia nos llamó especialmente la atención el que llevaba la signatura antes mencionada. Las razones que motivaron nuestra atención fueron que es el único que se conservaba en este archivo que lleva la específica denominación «De castrorum Valentie» (2), además al interesarnos los temas alicantinos, dado que Alicante fue zona de frontera, sería fácil hallar en este rgistro documentación referente a los castillos de la zona sur del Reino de Valencia.

Visto este volumen comprobamos que casi en su totalidad hacía referencia a castillos alicantinos y concretamente a los de Penáguila, Orihuela, Guadalest y Alicante, pero sobre todo al de Biar (3). La documentación que allí se nos ofrecía era variada, desde el punto de vista de su contenido: confirmaciones, nombramientos y juramentos de alcaides, devoluciones de castillos y por lo tanto, levantamiento del juramento de fidelidad. Si nos atenemos a los aspectos diplomáticos, y utilizando la tipología de Cabanes Pecourt (4), encontramos provisiones y cartas. De estos dos grupos vamos a limitar nuestro estudio a las provisiones que hacen referencia solamente al nombramiento de alcaides. En total se contienen en este registro siete de ellas tres corresponden a Biar y las restantes a Alicante, Orihuela, Guadalest y Penáguila.

(2) No entramos en los diferentes tipos de registros que pueden utilizar los monarcas de la Corona de Aragón.

(3) Diferentes aspectos sobre éstos castillos pueden verse en:

V. MARTINEZ MORELlA, Castillos y fortalezas de la Provincia de Alicante, Alicante, 1951

R. AZUAR RUIZ, Castellología Medieval Alicantina: area meridional, Alicante, 1981

(4) M.D. CABANES PECOURT, Particularidades diplomáticas de la cancillería de Alfonso $V$, en Anales de la Universidad de Alicante, Estudios medievales, I (1982)

F. SEVILLANO COLOM, Cancilleria de Fernando I de Antequera y Alfonso $V$, en «Anuario de historia del Derecho Español $», 35$ (1965) p. 269-296. De la Cancillería de la Corona de Aragón, en Miscelanea de estudios dedicados a Martínez Ferrando, Barcelona, 1968, p. 450.480

F.C. CASULA, II documento regio en la Sardegna Aragonesa, Padova, 1973

Sólo mencionamos los trabajos que afecta directamente al de Alfonso V o las que tratan aspectos generales. 


\section{2. - ESTUDIO DE LOS DOCUMENTOS}

El estudio de los documentos propuestos, vamos a hacerlo según la óptica y estructuración de Auguste Dumas (5) y utilizado en los trabajos de alguno diplomatistas españoles (6). Lógicamente algunos de los elementos no podremos analizarlos porque según hemos dicho vamos a trabajar los documentos de un registro y no sobre los originales.

Así pues el esquema propuesto sería:

I. - Protocolo

$$
\text { 1.1. - Formas de fuera del tenor }
$$

1.1.1.- Marcas validatorias

Suscripciones

Signos

Sellos

1.1.2. - Marcas de cancillería

Soporte y tinta

Escritura

Lengua y estilo

1.2. - Formas en tenor

$$
\begin{aligned}
\text { 1.2.1. - } & \text { De confianza } \\
& \text { Invocación } \\
& \text { Adprecación } \\
& \text { Corroboración } \\
& \text { Data } \\
\text { 1.2.2. - } & \text { De cortesía } \\
& \text { Intitulación } \\
& \text { Dirección } \\
& \text { Salutación }
\end{aligned}
$$

(5) A. DUMAS, La diplomatique et la forme des actes, "Le Moyen Age» XIIII (1932) p. 5-31.

Etude sux le classement des formes des actes "Le Moyen A ge", XLIII (1933) p. $81-87$, 145-182; XLIV (1934) p. 17-41.

(6) A. CANELlAS, Diplomática-hispano visigoda, en Miscelánea de estudios dedicados al profesor Antonio Marín Ocete, I (Granada, 1974), p. 87-183. Diplomatica Hispano visigoda, (Zaragoza, 1979)

L. NUN̂EZ CONTRERAS, Colección diplomática de Vermudo $I I$, rey de León Sevilla, 1978, es tirada aparte de Historia, Instituciones y Documentos IV (1977)

Concepto de documento, Archivística, (Sevilla, 1981), p. 25-44.

$M^{2}$ L. CABANES CATALA, Un documento de escritura visigótica en el archivo del Reino de Valencia, «Archivos Leoneses», 69 (1981)».: 194-197 
2. - Texto documental

2.1. - Dispositivo

2.2. - Accesorios preliminares

Notificación

Preámbulo

Exposición

2.3. - Accesorios complementarios

Mención de solemnidades

Sanciones

\section{1. - Protocolo}

\section{1. - Formas fuera del tenor \\ 1.1.1.--Marcas validatorias.}

No podemos analizar ni las suscripciones ni los sellos ni otros signos, simplemente a través dę la lectura de los documentos y del aspecto exterior que se recoge en los registros, el documento original llevaría la suscripción autógrafa. En el caso de que el documento esté dado por el rey, suscribiría con «Rex Alfonsus», si se trata de uno dado por su esposa María la suscripción sería «La reyna». (6)

Asimismo irían validados con sello de cera pendiente, tal y como se indica en la clausula final del anuncio de signos de validación: in cuius rei testimonium presentem fieri iussimus comuni sigillo regio inpendente minitam» (8)

\subsection{2. - Marcas de cancillería}

Soporte y tinta. - Como hemos dicho los documentos que estudiamos se contienen en el registro 24 de la sección de Real Cancillería del Archivo del Reino de Valencia. Las características de éste, en cuanto a los elementos materiales son los siguientes: se trata de un volumen formado por cuatro cuadernos de número desigual de hojas, 13 - ha perdido una - 10, 4 y 2 respectivamente. La filigrana es de las denominas «carro» (9) La encuadernación es de pergamino, de las llamadas de solapa. Cierra con un botón de pergamino y presilla. Lleva refuerzos de cuero en el lomo. Sobre la

(7) Apendice $\mathrm{n}^{\circ}$ 1, A.R.V. Real Cancilleria, 2, fol. 16V.

(8) A.R.V. Real Cancilleria, 24, fol. 16V.

(9) C.H. BRIQUET, Les filigranes (New York, 1966)

L. ARIÑO; Filigranas de Mosqueruela, en Ligarzas, 7 (Valencia, 1974) p. 121-360.

$M^{a}$ L. CABANES, M. CARCEL, C. Yago, El archivo de la colegiata de Jàtiva, en Ligarzas, 7, (Valencia, 1974) p. 1.-121. 
cubierta se puede leer "Cast ${ }^{4}$ Valeni Alf. iii Armario 83, $n^{\circ} 1 \mathrm{~A}$ ». Sus dimensiones son 30 por $23 \mathrm{~cm}$.

La tinta es de color rojizo

La escritura: - Los documentos allí contenidos van desde marzo de 1416 hasta junio de 1431. Dentro de esta amplitud cronológica hemos de encuadrar dos escrituras: por un lado de la gótica cursiva, típica de una larga etapa de la cancillería de la corona de Aragón (10) y otro, cuya introducción en la Península, es precísamente a travês de estos Estados, la humanística. (11)

En lugar de dar una descripción pormenorizada de ambas escrituras, ofrecemos láminas donde se recogen ambos alfabetos.

Lengua y estilo: En todos los casos la lengua utilizada ha sido la latina. En cuanto al estilo empleado es el clásico y usual de la cancillería de la Corona de Aragón.

\section{2. - Formas del tenor}

2.1 - Fórmulas de cortesía- Sólo hemos encontrado la data, que se inicia en todos los casos con la expresión «datum»; le sigue la indicación del lugar, es decir, la fecha tópica, en genitivo locativo o en ablativo precedida de in. La crónica, formada por el día - utiliza el sistema directo - mes y año expresado según el estilo de la Navidad. Se cierran los elementos cronológicos con el año del reinado. Este último elemento no es constante y falta en algún documento. Tanto si el documento lo expide el rey como si lo hace la reina, los años del reinado hacen referencia a Alfonso V (12)

1.2.2. - Fórmulas de cortesia.

La intitulación.- Como los documentos que estudiamos lo hacemos en registros, esta solo consta de pronombre, nombre - del monarca o de la reina - y etcétera (13). Lógicamente, si tuviéra-

(10) M. USON SESE, Contribución al estudio de la cultura medieval aragonesa del siglo $X I$ al XVI, (Zaragoza, 1940) p. 31.

A. FLORIANO CUMBREÑ. Curso general de Paleografía y diplomática españolas, Oviedo, 1946 p. 482.

F.C. CASULA, Breve storia della scritura in Sardegna, p. 86 y sig,

(11) L. D'ARIENZO, Alcune consideracioni sul pasagio dalla scrittura gotica all'umanistica nella produziones documentaria catalana dei secoli $X I V$ e $X V$, Studi di $P a$. leografia e Diplomatica, Padova, 1979, p. 199-226

(12) A.R.V. Real Cancilleria, 24, fol. 23V: "Datum Dertuse, die XXXI decembris, anno a Nativitate Domini $\mathrm{M}^{\circ} \mathrm{CCCC}^{\circ} \mathrm{XXX}^{\circ}$ " Apendice, 1

(13) A.R.V. Real Cancilleria, 24, fol 2V: Nos Alfonsus etc. fol. 16V Nos Maria etc. 
GOTICA

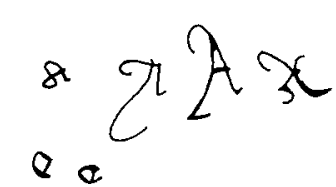

c 6

5

$$
?
$$
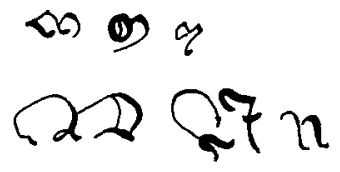

0
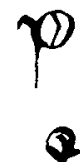

$$
\text { * }
$$

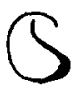

4

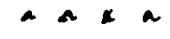

6' 6

c

09

e

$\begin{array}{ll}f & 6 \\ 3 & 5 \\ 3 & 8\end{array}$

1

680

m

n

0

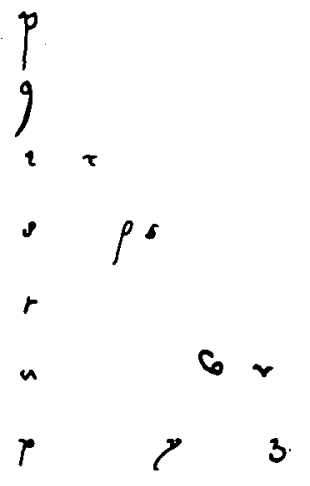

.1 a m. 2

Ia. m. 1

186 
HUMANISTICA

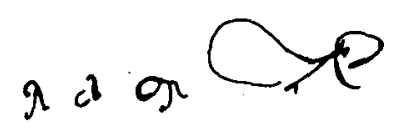

a

c

$6 e$

3

$\mathscr{L}$
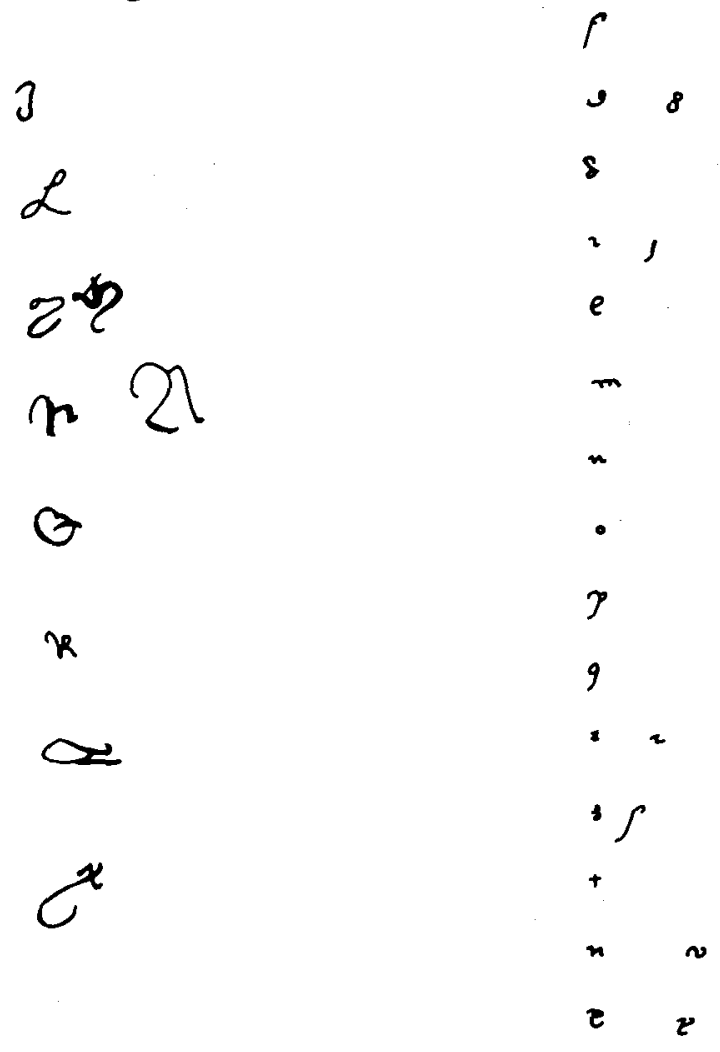

1 a m. 3

I am. 4

187 
mos los originales, tras el nombre figuraría al expresión de origen divino de la realeza y la de dominio precedida por los títulos correspondientes (14)

La dirección. - Suele constar de los siguientes elementos: pronombre - vos - un adjetivo sobre la calidad de la persona a la que va dirigido el documento - fidelem nostrum - y el nombre - vos fidelem nostrum Iohannem Martorell (15). A veces se indica incluso el lugar de donde es el destinatario - vos fidelem nostrum Luduvicum civem Valencie (16). En el caso del nombramiento de alcaide para el castillo de Alicante la dirección es aún más larga. Se inicia, como en todos los casos, con el pronombre, seguido de un calificativo y de los cargos que desempeñaba - consejero y mayordomo-según indica la reina María que es la que expidió el documento; ruestri dilecti consiliario et maiordomi dicti domini regis Iohannis Pardo de la Casta, militis iunioris (17)

La exposición. - Es otro de los elementos constantes es estos documentos, aunque de las dos clausulas de que consta, espontaneidad y motivación, sólo figura la segunda. La motivación en casi todas las ocasiones recoge el deseo real de premiar los servicios prestados a la corona.

La confirmación del castillo de Biar a Juan Martorell, en 14l6, está movida por los grandes servicios que prestó a su padre Fernan. do I y por ello lo sigue manteniendo como alcaide del mencionado castillo (18) Unos años más tarde, en 1419, vuelve a encomendarle el cuidado de la misma fortaleza y en este caso alega lo bien que desempeña el cargo, la voluntad del monarca de premiar los servicios, ampliar el favor de su subdito y la propia solicitud por parte del interesados. (19)

Cuando encarga a Pedro de Esplugues el cuidado del castillo de

(14) M.D. CABANES PECOURT, Particularidades diplomaticas...

(15) A.R.V. Real Cancilleria, 24, fol. 2V.

(16) Apendice 1

(17) A.R.V. Real Cancilleria, 24, fol. 16V.

(18) A.R.V. - Real Cancilleria, 24, fol, 2V, «...gratiucis serviciis legaliter illustrissimo domino regi patri et predecessori nostro memorie gloriose et nobis impensis...

(19) A.R.V. Real Cancilleria, 24, fol. 8, t... attendentes... ex comissione serenissimi domini regis Ferdinandi, genitor nostri recolende memorie, alcaydiam nostri de Biar, in Regno Valencie situati, ad bene placitum obtinere vosque qui circa dicte officii regimen bene et legaliter vos gessististi et gratis de presentia respectu nostrorum serviciorum et ampliacionem gratiarum et favoris promereri...» 
Orihuela, lo hace llevado por la costumbre de confirmar a los alcaides ya existentes, y porque se lo había prometido a su padre. (20)

En 1419 Alfonso V encarga a Luis Ibáñez, ciudadano de Valencia, la custodia del castillo de Penáguila. Tal honor le es concedido por los servicios que prestó, por la consideración que merece y además porque en esos momentos no existe alcaide en el mencionado castillo. (21)

Cuando Alfonso V marcha a Italia, por primera vez, deja como lugarteniente a su esposa María (22) Esto hace que cuando haya que nombrar nuevos alcaides los nombre la reina. Así en 1423 designaba a Juan Pardo de la Casta como alcaide del castillo de Alicante, por su fidelidad, por los buenos servicios prestados por su familia y porque se daba la circunstancia de que el alcaide anterior había muerto. (23)

Los otros nombramientos que estudiamos corresponden a Juan de Vera, quien en 1423 recibe la castellanía y la bailía de Guadalest y a Francisco de Ciscar, quien en 1430 recibe la encomienda del castillo de Biar (24) Las causas de tales nombramientos son semejantes a las expuestas en otros casos: premios a servicios (25)

\section{2. - Texto documental}

\section{1. - Dispositivo}

La disposición en todos los textos viene introducida por unos verbos comunes: «comittimus sive comendamus». En todos los casos el dispositivo contiene a lemas la sujeción del castillo a la "consuetudiem Yspanie». Existen pequeñas matizaciones dentro de estas líneas generales. Así, cuando reafirma en su cargo a Juan

(20) A.R.V. Real Cancilleria, 24 fol. $5 \mathrm{~V}$ «...quia per forum Regni Valencie et actum curie per predecessores nostros et nos iutratum et confirmatum officia inter cetera alcaydiatum concedi seu comitti non debent ad imperpetuum vitam beneplacitum vel ad tempus aliquibus personis nisi tamen trahendibus ortum seu habitatoribus vel heretatis sive fraude intus Regnum Valencie... quod serenissimus dominus rex Ferdinandus, genitor noster celebris memorie vobis utebo concessit nosque successive in initio anni regiminis..."

(21) Apendice 1.

(22) F. HERNANDEZ LEON DE SANCHEZ, Da María de Castilla, esposa de Alfonso V el Magnanimom, p. 83

(23) A.R.V. Real Cancilleria, 24, fol. $16 \mathrm{~V}$ «...de fide et legalitate, nec non ad grata servicia per vos et fratres vestros dicti domini regis et nobis impensa debitum habentes respetuum tenorem... vaccantem per obitum nobilis Franciscis de Vilanova..."

(24) Apendice 2 y 3

(25) Apendice 2 y 3 
Martorell, por primera vez, figura en el dispositivo la cantidad nual de su sueldo, 100 libras (26). La encomienda a Luis Ibáñez del Castro de Penaguila, además de los elementos comunes ya señalados, especifica que su sueldo será de 1,000 libras (27). Una variante interesante representa la entrega de Guadalest, ya que va a delimitar la zona de influencia; Castellanía y bailia del valle de Guadalest, de las montañas de Sarrià hasta el coll de Rates. Además la entrega se hace para él y para su hijo, con un salario anual de 3,000 sueldos (28)

Los restantes nombramiento no aportan ninguna novedad (29)

\section{2. - Accesorios complementarios.}

Las clausulas finales. - En todos los documentos encontramos de dos tipos. Una inyuntiva dirigida a todos los oficiales del Reino, a los que comunica los respectivos nombramientos y ordena que se les deje desempeñar su cargo según lo establecido (30) y la clausula de anuncio de signos de validación que presenta diferentes formas (31). A veces lleva una clausula obligativa (32)

Para finalizar, veamos la estructura documental y los escribanos. Respecto al primer aspecto, en todos los casos el documento se inicia con la intitulación - nos Alfonsus etc - le sigue la exposición, dentro de la cual suele ir inmersa la dirección, y tras aquélla la disposición con los verbos dispositivos ya citados. El texto se cierra con una clausula inyuntiva, a veces le sigue una obligativa. El conjunto de clausulas se clausura con el anuncio de los signos de validación.

El documento finaliza con las fechas tópica y crónica, la suscripción del rey y las diferentes marcas de cancillería, entre las que se recoge la «iussio». Es precisamente aquí donde figuran los nombres de los escribanos, pero ¿a qué escribanos se refiere? ¿a los de manament o a los de registre? (33). Pensamos que deben ser los

(26) A.R.V. Real Cancilleria, 24, fol. 2V.

(27) Apendica 1

(28) Apendice 2

(29) A.R.V. Real Cancillería, 24, fol. $2 \mathrm{~V}$ y $3 ; 5 \mathrm{~V}$ y $6 ; 8$ y $8 \mathrm{~V} ; 26$ y $26 \mathrm{~V}$ : Apendice 3

(30) Apendice 1, 2, 3

(31) Apendice 1,2 y 3

(32) A.R.V. Real Cancilleria, 24, fol. 26-26V «...ab eodem debito iuramento et homagio de tenendo et custodiendo dictum castrum.... "

(33) F. SEVILLANO COLOM, Apuntes para la Cancilleria de Pedro IV, en Anuario de Historia del Derecho Español, XX (1950) p. 179 y sig. 183 y sig. 
primeros. A continuación damos una lista de los mismos con las fechas en las que aparecen.

Paulus Nicholai, 1416-1419

Petrus Margall, 1419

Franciscus d'Arinyo, 1419-1424

Iohannes Olzina, 1430.

1419, noviembre, 30. San Cugat del Valles

\begin{abstract}
Alfonso V nombra como alcaide del castillo de Penáguila a Luis Ibañez, con un salario anual de 1,000 sueldos reales de Valencia
\end{abstract}

A.R.V. Real Cancilleria, 24, fol. 10v - 11

Nos Alfonsus etc. Quia graciosa obsequia per vos fidelem nostrum Luduvicum Iohannis, civem Valencie, nobis impensa dum ad ea consideracionis nostre occulte vertimus non modo subscripte sed uberioris gracie vos bene meritum representant tenore presentis, attendentes quod castrum et Penagua, villa de Penaguila, in Regno Valencie situata ad nostri speciatur dominum pervenire de proximo et seduci in quorum reduccione procuranda vos oppere et auxilio astitistis pro nostro servicio de fide et legalite vestri ad plenum confisi ex nunc pro tunc comitimus sive comendamus vobis Ludovico Iohannis, predicto, castrum predictum et eius custodiam quamdiu nostre placuerit volluntati. Ita quod Luduvicus, iam dicto, dum nobis placuerit ut prefacitur sitis alcaydus castri predicti ipsumque teneatis et custudiatis pro nobis ad usum et consuetudinem Ispanie fideliter, legaliter atque bene volentes et concedentes vobis quod pro remenat $/ / 10^{\mathrm{V}}$ dicti castri habeatis et recipiatis mille solidos regalium Valencie, annuatim et alia iustaque per alios alcaydos dictum castrum tenens fuera solito recipi et haberi. Mandantes, igitur, per hanc eandem gubernatori et baiulo generali Regni Valencie, nec non baiulo, iustice et iuratis ac hominibus dicte ville qui nunc sunt et erunt quod procesor de certa sciencia expresse sub obtentu nostre guere et mercedis quatenus vos dictum Luduvicum pro alcaydo dicti castri habeant et teneant vobisque pareant et attendant prout aliis alcaydis et attendere consueverunt et debent nec vobis annis singulis de dictis mille solidis pro retinencia antedicta ex aliis iuribus antedictis respondeant integre et complete et non contraveniant graviter causa. In cuius rei testimonium nobis fieri iussimus nostro sigillo inpendenti munitam

Datum in monasterio sancti Cucufati Vallensis, die tricesima novembris anno a Nativitate Domini $\mathrm{M}^{\circ} \mathrm{CCCC}^{\circ} \mathrm{XVIIII}^{\circ}$, regnique nostri quarto.

Rex A-lfonsus

Dominus rex mandavit mihi Francisco d'Avinyo

1424, agosto, 5. Barcelona

Alfonso V nombra a Juan Martinez de Vera castellano y baile del valle de Guadalest, con un salario anual de $\mathbf{3 , 0 0 0}$ sueldos reales de Valencia

A.R.V. Real Cancillería, 24, fol. 18v-19

Castellanie et baiulia vallis de Guadalest et montenearum apellatarum de Serria pro Iohanne Martinez de Vera, milite

Nos Alfonsus etc. Ad grata et accepta servicia per vos dilectum nostrum Iohannem Martinez de Vera, militem, tam predecessoribus nostri quam nobis diversi mode prestita et que in- 
pendere non cessatis animo in deffesso debito habentes respectum tenore presentis in aliqualem dictorum serviciorum remuneracionem et premium vobis dicto Iohanni, tanquam benemerito et condigno vita vestra durante et post uni heredi vestro quam in testamento aut aliis duxeritis eligendum castellaniam et baiuliam vallis de Guadalest et montanearum appellatarum de Serria ultra collem de Rates in Regno Valencie situatim, cum salario trium mille solidorum monete reagalium Vajencia anno quolibet tribus et terciiis vobis dicto vestro herede solvendorum ex nunc cum ad nostrum dominum pervenerint prout pervenire sperantur dicimus comittendas, tenendas, regandas et exercendas per vos dictum exertitis et post per vestrum heredum predictum feliciter legaliter atque bene vos vita vestra post dicti heredis vestri durante ut est dictum sitis alcaydus et baiulus vallis et montanearum predictarum et habeatis et recipiatis pro retinencia, salario et regimine castellanie et baiulie predicte salarium premencionatum ac alia iura et emolumenta que per castellanos et baiulos vallis et montanearum predictarum fuerit soleta recipi et haberi. Mandantes per eandem gerentivices gubernatoris ac baiulo generali Regni Valencie, iuratis, probis hominibus et habitatoribus vallis et montanearum iamdictarum presentibus et futuris et aliis ad quos spectet quatenus vos dictum Iohannem dum vixeritis post vitam propriam heredem vestrum iamdictum dum vixeritis pro castellano et baiulo predicto de cetero habeant et teneant vobisque ipsi ac ordinacionibus et iussionibus $/ / 18 \mathrm{v}$ vestris et ipsius pareant, obediant in et de omnibus his de quibus prout aliis aliud qui castellaniam et baiuliam predictas tenuerunt et rexerunt parece et obedire consueverunt et debent etiam et tenentur nec non respondeant vobis et dicto vestro heredi vita vestra et ipsius durante ut predicitur de salario et retinencia supradicta ac aliis iuribus assuetis. In cuius rei testimonium presentem fieri iussimus nostro sigillo comuni inpendenti munitam

Datum Barchinone, quinta augusti anno a Nativitate Domini millesimo CCCCXXXXIIII ${ }^{\circ}$, regnique nostro nono

Rex Alfonsus

Dominis rex informatus de vita, mandavit michi Francisco d'Arinyo. Provisa

\section{Alfonso V concede la alcaidía de Biar a Francisco de Císcar}

\section{A.R.V. Real Cancillexía, 24, fol 27-27V}

Nos Alfonsus etc. In nostre serenitatis aciem sollicite resol vents ingeni ac corporis obtitendum prudentie ac morum prospicuitate pureque fidei sinceritatem, vestri dilecti camerario nostri Franciscis de Siscar, milites, recolentes necminus comendatabili more duras labores, lataque dispendia, et supretuum multiplicium incomoda per vos diversi mode posse panterter sustente nostre aptis culmen quadam devota satis obsequiorum imperium cum vestrarum armorum gentium cantituis detende obseqidantes in aliqualem, itaque serviciorum predictorum recompensam licet maioris restribucionis previsum mereatur assequi tenoris presentis alcaydiam de Biar, vaccantem, pro nunc per seginacionem die presenti in manibus nostris factam per dilectum camerarium nostrum Guillermum de Vico, militem cobis eidem Francisci ad vite vestre curriculum prestitito per vos prens iuramento et homagio detenendo et custodiendo dictum castrum, legaliter atque bene ad nostrum servicium et honorem et alias ad usum et consuetidinem Yspanie, ducimus, committendam ita quod vos suis alcaydus dicti castri et previque teneatis et custodiatis ad usum et consuetudinem Usanie et habeatis. et re. cipiatis pro retinencia catri eiusdem ea iura et salaria preheminencias et prrogativas et honres et alia etiam omnia que per dictum Guillermum etiam alcaydos qui nunca usque dictum renucenter castro sunt solita et haberi. Mandantes per eandem gubernatorigenerali eiusque vicegerentibus et baiulo generali Regni Valencie, ceterisque officialis et subditis nostri ac vicinis habitatoribus dicti castro, presentibus et futuris quatenus vos dictum Franciscum de Siscar por alcaydo dicti castri habeant et teneant quamdiu vixeritis ut est dictum 
vobis pareant et respondeant et obedient de salario iuribus prerogativas, honoribus $/ / 27$ et preheminentiis, et aliis etiam quibuslibet de quibus iamdicto Guillermo de Vico et ceteris al. caydis dicti castri est pereti et responderi hanctenus assuetum. In cuius rei testimonium presentem fieri iussimus nostro sigillo comuni inpendenti munitam

Datum Dertuse, die XXi ianuario anno a Nativitate Domini $\mathrm{M}^{\circ} \mathrm{CCCC}^{\circ} \mathrm{XXX}^{\circ}$, regnique nostri XV

Dominus rex mandavit mihi Iohanni Olzini. Provisa 